\title{
1 Superciliums in white-eared hummingbirds as badges of status
}

\section{2 signaling dominance}

4 a Juan Manuel González-García, ${ }^{\mathrm{b}, *}$ Carlos Lara, ${ }^{\mathrm{c}}$ Javier Quesada, ${ }^{\mathrm{d}}$ Carlos A. Chávez-Zichinelli,

$5 \quad$ e Martín A. Serrano-Meneses

6

7 a Doctorado en Ciencias Biológicas, Universidad Autónoma de Tlaxcala, Carretera Tlaxcala-

$8 \quad$ Puebla Km 1.5, 90070 Tlaxcala, Mexico.

9

10 bentro de Investigación en Ciencias Biológicas, Universidad Autónoma de Tlaxcala, Km 10.5

11 Autopista Tlaxcala-San Martín Texmelucan, San Felipe Ixtacuixtla, Tlaxcala 90120, Mexico.

12

$13{ }^{\mathrm{c}}$ Natural History Museum of Barcelona, Chordates Laboratory, Passeig Picasso s/n, 08003

14 Barcelona, Spain.

15

16 dEl Colegio de Puebla, Calle Tehuacán Sur 91, La Paz, 72160 Puebla, Puebla, Mexico.

17

18 éniversidad de las Américas Puebla Sta. Catarina Mártir. Cholula, Puebla. C. P. 72810, Mexico.

19

20 *Author for correspondence; email: carlos.lara.rodriguez@gmail.com

21

22 Running head: Badges of status signaling dominance in hummingbirds 
1 Abstract The role of badges as indicators of contest ability has been previously described. In

2 hummingbirds, the exhibition of a badge is expected to save energy expenditure in agonistic

3 interactions and to favour energy intake. Here we investigate whether variable supercilium size

4 in the white-eared hummingbird has a role in dominance status signaling. Firstly, 45

5 hummingbird males were captured and their superciliums were photographed to investigate

6 variation in size and any possible allometric relationships. Secondly, 42 male birds were used to

7 analyze whether the supercilium has a role in dominance status signaling in a dyadic contest. We

8 found that supercilium size varied continuously but that, despite variability between individuals,

9 there was no relationship between supercilium size and body size. However, our dyad

10 experiment indicated that birds with larger badges were able to make more visits to the feeders

11 than individuals with smaller badges. We suggest a status signaling function of the supercilium.

12

13 Keywords dominance, Hylocharis leucotis, recognizing dominance, signal reliability, status

14 badge 


\section{Introduction}

The most common means of resource-holding in animals is territoriality, that is, the basic behavior of a resident individual aimed at defending and excluding others from a specific area (Brown and Orians 1970). Prior to a territorial dispute, contesting individuals are often able to evaluate each other through the use of signals that are reflections of their inherent ability in a contest (Smith and Harper 1995; Rat et al. 2015). The signals used for either a context of intrasexual competition for sexual resources (e. g. mates) or social competition for food resources involve similar traits, such as conspicuous displays, weaponry, aggressive behaviors, and costly signals (Tobias et al. 2012). These types of signals have been found in many avian species and include auditory cues and visual signals associated with plumage - e.g. the size of ornaments and both pigmented or structural plumage coloration - that prevent birds from engaging in costly contests with predictable outcomes (Rohwer 1975; Smith and Harper 2003; Senar 2006; Pryke 2013).

The conspicuous coloration patches in the plumage of many birds that are made up of different pigments, termed by convention 'badges', often reflect different individual health and condition (e. g. carotenoids) but mostly reflect social status (e. g. melanin-based colours) (Rohwer 1975; Senar 2006; Santos et al. 2011; Young et al. 2015). The role of badges as indicators of contest ability has been analysed, above all, in bird species from temperate areas of the world via the evaluation of territorial performance of individuals exhibiting a gradient in the size and/or intensity in their badges (i.e. Møller 1987; Senar et al. 1993; Rémy et al. 2010; Quesada et al. 2013; Mercadante and Hill 2014). These studies have shown that larger and brighter badges (less dark) indicate better competitive abilities. 
Generally, the maintenance and development of these visual signals are energetically

costly, which makes them reliable signals (Zahavi 1975; Husak et al. 2015). Ornament

production and maintenance have associated drawbacks: they may increase the risk of predation (Endler 1978; Stuart-Fox et al. 2003; Pascual and Senar 2014), reduce immune-competence (Ressel and Schall 1989; Dunlap and Schall 1995; Salvador et al. 1996; Calisi et al. 2008) and have social costs in the event of aggressive contests that are both physiologically expensive and time-consuming (Tibbetts and Dale 2004). Therefore, the ability to exhibit this type of signal may be an honest indicator of an individual's health and its physical capabilities in a contest (Hamilton and Zuk 1982; Folstad and Karter 1992), particularly if these traits are more exaggerated in larger-than-average individuals (hyperallometric). This is because, according to indicator traits (Gould 1974; Petrie 1988, 1992), only males in overall good conditions will be able to invest relatively more on these traits with respect to body size (Álvarez, et al. 2013). Disentangling these various factors is a challenge for the current signaling theory underlaying that the evolution and maintenance of these badges are still poorly understood.

White plumage ornaments, however, have often been assumed to be inexpensive because their production requires neither pigment nor specialized feather structure (McGlothlin et al. 2007). Proposed mechanisms for maintaining the honesty of unpigmented signals have usually focused on various costs of maintaining the trait, such as greater risk of feather abrasion and breakage, colonization of keratinolytic bacterias, reduced attractiveness or its role of inducing male-male aggression (Fitzpatrick 1998; Kose and Møller 1999; Török et al. 2003; McGlothlin et al. 2005; Justyn et al. 2017). But some studies have shown trade-offs between life history traits such as brood size (Gustafsson et al. 1995) and diet quality (McGlothlin et al. 2007) in the 
expression of white plumage patterns, which suggest a role as honest signals of individual quality.

Hummingbirds (Trochilidae) are endemic to the Americas and are the second most diverse family of birds in this continent (approximately 350 taxa). These small birds inhabit all types of environments (Schuchmann 1999) and are known for their agility in flight, high metabolism, iridescent plumage, and both anatomical and physiological adaptations to a specialized diet of nectar (Stiles 1981). Hummingbirds have physiologically demanding flying abilities, which is fueled by the energy obtained from the flowers they visit, while also having evolved due to their feeding strategies (Wagner 1946; Wolf et al. 1976; Stiles 1995; Altshuler et al. 2004). As a result, competition (through territorial behavior) for feeding territories between certain hummingbird species is frequent and plays an important role in determining the structure of their communities (as opposed to the trapliner behavior displayed by non-territorial hummingbirds in which an individual visits food sources on a regular repeatable sequence involving an specific route) (Feinsinger and Colwell 1978; Montgomerie and Gass 1981; Hixon et al. 1983; Dearborn 1998; Camfield 2006)

Dominance (both intra and interspecific interactions) in hummingbirds has been found to be associated with the individual physical state, sexual dimorphism, body size, wing disc chord loading, species identity (e. g. some species dominate others at floral patches or feeders) and territorial quality (Kodric-Brown and Brown 1978; Carpenter et al. 1993; Ornelas et al. 2002; Stiles et al. 2005; Németh and Moore 2012). These characteristics have been postulated and tested in hummingbird species at particular moments of their biological cycles such as migration and reproduction (i.e. Gass 1979; Ewald 1985). It has also been suggested that variation in behavioral profile or "personalities" may affect the establishment of dominance relationships and 
82 risk sensitivity, where previous research has found hummingbirds to show a steroid-correlated

83 boldness scale (Goloff and Burch 2012; Chávez-Zichinelli et al., 2014). However, despite male

84 hummingbirds employ their iridescent plumage (visual signals) in a variety of contexts,

85 including nuptial displays, aggressive sexual displays, and aggressive displays associated with

87 (iridescent or not) and badges during territorial intra and interspecific disputes has only rarely been examined (but see Ewald and Rohwer 1980). This is somewhat surprising, above all if we note that not iridescent signals such as the postocular lines - often white in colour (hereafter referred as superciliums) - are common in hummingbirds. For example, 56 out of the 70 hummingbird species that occur in Mexico and North and Central America (Howell and Webb 1995) have some type of white spot or patch on their heads (males, females, and juveniles). The white-eared hummingbird (Hylocharis leucotis) earns its common name from its supercilium (this patch is not iridescent, so it can be observed at all angles, not specific ones). As opposed to the trapliner behavior displayed by females, the males of this species establish feeding territories that they aggressively defend against conspecifics and other heterospecific small-sized hummingbird species (Lara 2006). When passively (e.g. territorial calls) or actively (e.g. chases and physical contacts) defending a territory, the supercilium is always visible, so that this signal is obvious to any intruders during a territorial contest (hence we focus here only in males). In this study, dominance is defined as success in intraspecific contests, a synonym for resource holding potential, i. e. individuals with the higher resource holding potential (RHP) win disputes (Parker 1974). Thus, resource holding potential reliably reflects male quality. Hence we hypothesized that the supercilium could play a role in signaling to intruders an individual's resource-holding potential, where individuals with larger-sized superciliums will tend to 
monopolize the available resources, i.e. pay more frequent visits to a food source, to the detriment of individuals with smaller-sized superciliums. However, many supposed ornaments that could be related to dominance may actually signal other qualities such as age or size (see Senar 2006 for a discussion), aspects that require consideration in signaling studies. The goals of our study were thus (1) to assess supercilium size variation in males captured in natural conditions and analyze its possible relationship with body size (allometry). This first approach allowed us to rule out possible allometric effects on supercilium size. Subsequently, (2) we used a manipulative approach to experimentally evaluate the role of supercilium size as a badge of status signaling dominance.

\section{Methods}

\section{Study site and species}

From February 2013 to March 2015, white-eared hummingbirds (Hylocharis leucotis) were studied in La Malinche National Park (LMNP), Tlaxcala, Mexico (19²14'N, 98 $58^{\circ} \mathrm{W}, 3000 \mathrm{~m}$ a.s.1.). Ethical approval was received from the relevant local authorities (SEMARNAT, license number FAUT-0296). The vegetation in the study area consists mainly of a mosaic of pine forest and second-growth vegetation (Villers et al. 2006). These small hummingbirds (ca 3.1-3.4 g) are residents in LMNP and both sexes feed throughout the year on a wide range of hummingbirdpollinated plants (Lara 2006). Males are highly territorial and are frequently observed defending clumps of flowers on firecracker bushes Bouvardia ternifolia (Rubiaceae), beardtongues Penstemon roseus (Lamiaceae), and pineapple sages Salvia elegans (Lamiaceae). Both sexes have a distinctive white line above and behind the eye (supercilium), and their pigmented 
127 underparts are whitish, heavily speckled with green, but males have a bluish violet iridiscent

128 forecrown and chin, and a glittering green throat (absents in females).

\section{Natural variation in supercilium size}

131 To evaluate variation in supercilium size in males, 45 hummingbirds were captured with mist 132 nets in different areas of the LMNP, but most in areas where patches of flowering firecracker 133 bushes, beardtongues, and pineapple sages abounded. We took the following measurements from 134 each captured individual: (1) total length (mm), (2) bill length (mm), (3) tail length (mm), (4) 135 wing chord (mm), and (5) weight (g; sensu Pyle 1997). Body measurements were taken using a 136 digital caliper (Mitutoyo SC-6, $\pm 0.2 \mathrm{~mm}$ error) and a digital scale (US-SONIC-500, $0.1 \mathrm{~g}$ 137 resolution).

After measurements, the superciliums (on the right and left sides of head) of each

139 individual were laterally photographed twice with a digital camera (Sony Alpha SH0006) from a 140 constant position and distance. The number of pixels per square millimeter (area) and $1 \mathrm{~mm}$ 141 (linear) were calculated using a ruler to get the scale for each photograph using Adobe 142 Photoshop CS6. This methodology is commonly used in studies of plumage colour (Muck and 143 Goymann 2011). The photographed birds were marked by clipping the fifth rectrice (to avoid 144 pseudoreplication), and were then released back to sites from which they were captured. Time 145 from capture to release for each bird was approximately 20 minutes.

We assessed the repeatability of supercilium area by comparing the size estimated from 147 photographs 1 and 2 of only the left-side supercilium of each captured individual. These two 148 samples turned out to be highly repeatable for the same individual (adjusted repeatability: 0.92;

149 confidence interval, CI: 0.87-0.93, P < 0.0001; following Nakagawa and Schielzeth 2010). 

determined, we performed major axis regressions between supercilium size and body measurements (MA regression; Sokal and Rohlf 2012). MA regressions were performed using

153 the 'smatr' package in R (Warton et al. 2012), which calculates allometric slopes between two 154 continuous variables, as well as their 95\% confidence intervals (CIs; upper CI - lower CI). A 155 slope was considered to be significantly different from 1 if the confidence intervals excluded $\boldsymbol{\beta}=$ 156 1, and the associated P value was $\leq 0.05$ (Álvarez et al. 2013).

\section{Experiment: supercilium as a badge of status signaling dominance}

After discarding potential allometric relationships between supercilium size and body

measurements (see Results), we evaluated whether this badge has a role in signaling dominance status. Dominant individuals usually prevail over others and take a disproportionate share of available resources (Barnard 1984). Thus, here we considered an individual to be dominant if it made a greater number of visits to a feeder during an experimental trial (Tiebout 1996). A total of 42 adult hummingbird males were captured in the field using mist-nets (different individuals to those used for measuring badges). After capture, the males were measured following the protocol described above (including supercilium size). The birds were housed individually for 24

$167 \mathrm{~h}$ in collapsible field cages (dimensions: $1.5 \times 2.0 \times 1.5 \mathrm{~m}$ ), which contained a perch and a feeder 168 with $120 \mathrm{ml}$ of $20 \%$ (by mass) sucrose solution. During this period, feeding by the birds was 169 taken as evidence that they were acclimatized to the enclosure. Individuals that did not feed 170 during the first hour of confinement were released and not used for experimental procedures.

171 Prior to the trials, individuals were not fed for $20 \mathrm{~min}$ so that by the time of the experiment they 172 were presumably hungry. 
An experimental trial consisted of placing two captured individuals for 60 minutes in a

174 collapsible field cage with the characteristics described above, the only difference being the 175 existence of two perches. During this period, a videocamera (Panasonic Camcorder model SDR176 H4OP) recorded for both hummingbirds the latency of feeder visits, the number and duration of 177 visits, and the number of agonistic displays (physical contact between the two birds). The great 178 individual variation in the shape and size of the supercilium allowed us to distinguish the 179 individuals used in each dyad and to be able to collect their data. We predicted that the greater 180 the differences between contestants' supercilium sizes, the more differences there would be in 181 the magnitude of the evaluated variables. Based on variation across individuals, half of the male 182 dyads $(\mathrm{n}=11)$ had a specific supercilium-size difference ranging from $0-0.04 \mathrm{~cm}^{2}$ (similar 183 contenders), and the remaining half from $0.05-0.17 \mathrm{~cm}^{2}$ (different contenders). Thus, the 184 contests were classified into two types in terms of the differences in supercilium size between the 185 contenders (Contest type). For analyses we use patch size differences (that vary continuously) 186 among contenders. All subjects $(N=42)$ were used only once in the experiment and were 187 subsequently released as per the protocol described above.

To assess the contribution of differences in supercilium size between contenders to the intensity of feeder use during the experimental trials, two statistical approaches were used. In the

190 first approach, four separate regressions test each of the behavioural measures (dependent 191 variables: differences in latency of visits, number of visits, duration of visits, and number of 192 disputes between contenders) against difference in badge size (independent variable) and 193 considering the contest type (contestants with similar or different badge size). In the second approach, we used the R package 'Ime4' (Bates et al. 2014) to build five 195 candidate generalized linear mixed-effects models (GLMM), to be compared using an 
196 information theoretic approach (Burnham and Anderson 2002). All continuous variables were

$197 \log _{10}$-transformed prior to analyses. Each candidate model included supercilium size differences

198 among contenders as independent variable (predictor) and foraging and agonistic variables, and

199 contest type as dependent variables (response variables). Contest identity was included in the

200 models as a random effect due to variation shown in supercilium size in each dyad. For each

201 model an Akaike weight (Akaike 1981) was calculated, which indicates its level of support

202 (since Akaike weights sum to 1, models with Akaike weights approaching 1 receive the most

203 support relative to other models). By summing Akaike weights of all models containing a

204 particular variable, a measure of the relative "evidence of importance", for that predictor

205 variable is produced (Burnham and Anderson 2002). However, this value of predictor

206 importance does not indicate the magnitude or direction of the relationship between predictor

207 and response variables. To provide such an understanding, we subsequently used model

208 averaging to calculate the average parameter estimates based on all GLMM models in which the

209 parameter appeared, weighted by their Akaike weights. The BMS package was used to calculate

210 the posterior inclusion probability (PIP) and standardised posterior mean coeficient (PMC) for all

211 dependent variables. The prior probability for the model was set using the default, which uses the

212 median of the number of available parameters and draws from a normal distribution (of the

213 number of posible parameters).

214 All statistical analyses were performed using the software R (R Development Core Team 215 2014).

\section{Results}

\section{Allometry of supercilium size}


219 Supercilium size in male white-eared hummingbirds ranged between 15 to $35 \mathrm{~mm}^{2}$, with a mean

220 of $21 \mathrm{~mm}^{2}$ (standard error of $0.13 \mathrm{~mm}^{2} ; N=45$ ). Table 1 summarizes the calculated MA

221 regression slopes between supercilium size and the six male body-size measurements. The

222 results from the MA analyses showed that supercilium size is not allometrically related to body

223 size.

225 Supercilium size and dominance status signaling

226 No significant relationships were found between the differences in latency of visits (similar

227 contest types: $\mathrm{Y}=3.42 \mathrm{x}-6.6, \mathrm{R}^{2}=0.16, N=11, P=0.06$; different contest types $\mathrm{Y}=2.20 \mathrm{x}+6.12$,

$\left.228 \mathrm{R}^{2}=0.17, N=10, P=0.10\right)$, duration of visits $\left(\mathrm{Y}=1.13 \mathrm{x}-01.54, \mathrm{R}^{2}=0.06, N=11, P=0.54 ; \mathrm{Y}=\right.$

$\left.2290.97 \mathrm{x}+3.21, \mathrm{R}^{2}=0.02, N=10, P=0.51\right)$, and number of disputes between contenders $(\mathrm{Y}=0.10 \mathrm{x}$

$\left.230+5.24, \mathrm{R}^{2}=0.14, N=11, P=0.09 ; \mathrm{Y}=0.73 \mathrm{x}+0.48, \mathrm{R}^{2}=0.001, N=10, P=0.89\right)$, against

231 difference in badge size. However, we found a significant relationship between the difference in

232 number of visits to a feeder versus difference in badge size (Figure 1).

Table 2 summarizes the results of GLMMs investigating the effects of supercilium size on the foraging and agonistic variables, by considering contest type. Variance in supercilium size

236 among contenders had the stronger effect on the number of visits, with a posterior inclusion

237 probability value of 0.683 (Table 2 ). Thus, individuals with larger superciliums were able to 238 make more visits to the feeders (Figure 1) irrespective of contest type (i.e. of whether contenders 239 had similar or different supercilium sizes). All other dependent variables (latency of visits, 240 number of visits, duration of visits, number of disputes between contenders, contest type) did not 241 significantly contribute to the models tested. 


\section{Discussion}

244 Typically, the evolution of sexual traits and, in particular, their hyperallometric patterns, has

245 been explained by sexual selection given the supposed advantages that they confer in mate

246 selection or access to reproductive mates (Gould 1974; Petrie 1992; Kodrick-Brown et al. 2006).

247 However, the theory of social competence (Lyon and Montgomerie 2012) states that competition

248 for limited resources - rather than for mates - may also promote the use of such elaborate traits.

249 Our study demonstrated the lack of hyperallometry in supercilium size in white-eared

250 hummingbird males. These results, along with the demonstration that differences in badge size

251 between contestants affects the level of intraspecific dominance at a food source (feeder),

252 suggest that superciliums may be used as a status signal in a context of social competence.

The promiscuous reproductive system of hummingbirds (Stiles and Wolf 1979) seems to

254 favor the use of multiple signals to females (Candolin 2003; Chaine et al. 2013). For example,

255 these signals can serve as multiple messages that either indicate general mate quality or enable

256 females that differ in mate preferences to choose the most suitable male (i.e. the iridescent

257 plumage on cheeks and throat). Likewise, the function of these features as status signals of social

258 communication, particularly in a intraspecific territorial context, has been previously

259 demonstrated for both sexes in a number of different species (Wolf 1969; Ingles 1976; Stiles

260 1982; Bleiweiss 1985). However, to our knowledge this is the first documented study of the use

261 of non-iridescent plumage for status signaling in hummingbirds. More than 50 species of

262 hummingbirds in Mexico and North and Central America exhibit superciliums (Howell and

263 Webb 1995) and appear in both males and females in approximately $25 \%$ of these species. The

264 practice of territorial defense in both sexes in several hummingbird species has been used as an 
265 evolutionary explanation for the iridescent coloration in monomorphic species (Wolf and Stiles

266 1970); thus it is possible that this selective pressure may also be acting on non-iridescent

267 structural colorations such as the supercilium.

268 The white-eared hummingbird males evaluated in our study showed an important 269 variation in supercilium size (from 15 to $35 \mathrm{~mm}^{2}$ ), which was independent of body size. The 270 adaptive significance of intraspecific variation in plumage characters has received much 271 attention, and a large number of hypotheses have been advanced to explain the variation (e. $g$. 272 Butcher and Rohwer 1989; Lank 2002; Fowlie and Kruger 2003). Here, we suggest that 273 superciliums serve as badges and can be signals of intraspecific dominance when males are 274 foraging. But, our data could not determine whether supercilium size changes with age (this 275 would require a longitudinal study). However, given the lack of hyperallometry, it is possible 276 that supercilium (badge) size may be related to individual quality characters for dominance status 277 signaling such as body size (important in interspecific contests for nectar sources, e.g. Justino et 278 al. 2012), body condition and many other physiological factors. This relationship has been 279 established in other birds such as the american yellow warbler Setophaga petechia (Studd and 280 Robertson 1985), the house sparrow Passer domesticus (Møller 1987) and the eurasian siskin 281 Carduelis spinus (Senar et al. 1993). Here, we show that birds with larger badges were usually 282 more dominant over the food resource than individuals with smaller badges (individuals with 283 larger superciliums were more likely to visit the feeders), suggesting that white plumage patch 284 exhibited in male white-eared hummingbirds may act as a badge of intraspecific dominance 285 status. The small size and high metabolic rate of hummingbirds prevent them from surviving for 286 long if energy expenditure exceeds income (Kodric-Brown and Brown 1978). Because physical 287 conflict over limited resources (as occur in hummingbirds) can be costly in terms of both time 
and health (Chaine et al. 2013), the exhibition of a badge (i.e. supercilium) can save energy expenditure associated with competitive interactions and favor energy intake (individuals with larger badges are expected to have a better resource holding potential), such savings can be highly beneficial in a species with a such high metabolism.

Not all signals are honest (e. g. lures, sensory exploits, sensory traps) but when they are, this honesty is maintained by the cost of the signal (Zahavi 1975). Nutrients required to maintain the plumage pigments colours are different. For example, carotenoids are scarce in the environment and exclusively obtained from diet (Goodwin 1984), but melanins are synthesised from amino acids that are basic dietary components and usually not a limiting resource (Griffith et al. 2006). In this regard, the presence of white color patches on melanized body structures could be of particular importance because their size and brightness seem to be affected by rearing conditions, parasite infections and diet quality (Kose and Møller 1999; Gustafsson et al. 1995; McGlothlin et al. 2007). Hummingbirds do not have different breeding and nonbreeding plumages and molt only once per year. Because this process is stressful, birds usually molt during periods when there are neither breeding nor migrating (Williamson 2001). Likewise, parasite infection is common in hummingbirds not only in plumage but rather with gastrointestinal and blood presence, and so far little known effects (Matta et al. 2014). Therefore, it is expected that if despite the extra cost involved in molting and parasites, the size of a badge (i. e. supercilium) is maintained over time, then the honesty of the signal is reaffirmed, but studies are needed to prove it.

The most common type of agonistic interaction in territorial species occurs when an animal displaces an opponent and forces it to move away (i.e. Paton and Caryl 1986). However, due to the inherent costs of disputes, contestants can use their opponent's traits or features to 
311 avoid fights and aggressive interaction (Smith and Harper 2003). A number of studies have

312 demonstrated that this occurs in several bird species, mainly because sex and age are usually

313 associated with different plumage colorations (the dominant birds typically have darker or

314 blacker patches), and birds learn to associate coloration with the degree of dominance of a given

315 individual (Krebs and Davies 1987; Whitfield 1987). Plumage thus becomes, indirectly, a status

316 signal (i.e. Senar et al. 1993; Smith and Harper 2003; Quesada et al. 2013). Our study revealed

317 that individuals with larger superciliums showed an increased resource-holding ability (number

318 of visits to the feeder) compared to intraspecific contestants with small badges. These results

319 suggest that individuals are able to assess the difference in status of an opponent on the basis of

320 their relative supercilium sizes; thus, plumage will determine the outcome of any encounter

321 (Whitfield 1987).

It has been suggested that status signals should be selected above all in species with

323 unstable group composition or in species where contests are usually between individuals with no

324 previous social contact, as in these cases the cost of status assessment would be lessened

325 whenever two individuals confront each other (Rohwer 1982; Senar et al. 1990, Vedder et al.

326 2010). For example, high quality sites are often visited by many conspecific and heterospific

327 hummingbird species so that familiarity between individuals may be low and hence the

328 exhibition of reliable badges beneficial. In this respect, the males of most northern temperate

329 hummingbird species (and several tropical species) defend their territories by sitting on exposed

330 perches in the open, thereby providing visual signals to scare away potential intruders (Skutch

331 1940; Pitelka 1942).

Given that our data show that supercilium size was not related to body size, it is possible that other factors may explain why individuals with larger badges forage more in captivity. For 
334 example, Chávez-Zichinelli et al. (2014) showed that testosterone (T) levels seem to influence

335 foraging preferences in male white-eared hummingbirds and that individuals with higher levels

336 of T make quicker and more frequent visits to flowers with variable rewards - and behave

337 consistently as risk-prone foragers - than males with low $\mathrm{T}$ levels. These findings suggest that

338 behavioral profiles or personalities of the birds used in the dyadic contest could influence our

339 results. In this context, we predicted that individuals with larger badges should show higher

340 levels of steroids and have higher levels of boldness and intraspecific dominance. Such a study

341 could help us to understand the possible relationship between steroid hormones, badge size, and

342 the signaling of dominance status in hummingbirds, a topic heretofore unexplored.

In short, we showed that white-eared hummingbird males with larger superciliums had

344 enhanced access to the food resource than males with smaller superciliums: more visits to a

345 feeder than their adversaries suggests a role for superciliums in dominance status signaling.

346 Further future studies might seek to apply experimental manipulation, either artificially

347 modifying the size or presence of this trait in individuals within a dyadic contest, to verify the

348 status signaling function of supercilium.

Acknowledgements We would like to thank M. J. Pérez-Crespo and V. Mendiola for their

351 assistance in the field and their logistical support. To Mike Lockwood for the revision of the

352 manuscript in English. Pietro K. Maruyama and three anonymous reviewers provided useful

353 comments on previous versions of the manuscript. Permission to conduct our fieldwork was

354 granted by the Mexican government (SEMARNAT, FAUT-0296). This work constitutes partial

355 fulfillment of JMG's doctorate at the Universidad Autónoma de Tlaxcala. 


\section{Compliance with ethical standards}

358

Funding The Consejo Nacional de Ciencia y Tecnología (CONACYT: 365006/248109) provided the first author with financial support in the form of a scholarship. The funders had no role in study design, data collection and analysis, decision to publish, or preparation of the manuscript.

Conflict of interest The authors declare that they have no competing interests.

Ethical approval All experiments comply with the current Mexican laws

\section{REFERENCES}

Akaike H (1981) Likelihood of a model and information criteria. J Econom 16: 3-14. doi.org/10.1016/0304-4076(81)90071-3

Altshuler DL, Stiles FG, Dudley YR (2004). Of hummingbirds and helicopters: hovering costs, competitive ability and foraging strategies. Am Nat 163: 16-25. doi.org/10.1086/380511

Álvarez HA, Serrano-Meneses MA, Reyes-Márquez I, Jiménez-Cortés JG, Córdoba-Aguilar A (2013) Allometry of a sexual trait in relation to diet experience and alternative mating tactics in two rubyspot damselflies (Calopterygidae: Hetaerina). Biol J Linn Soc 108: 521-533. doi.org/10.1111/j.1095-8312.2012.02031.x

Barnard CJ (1984) The evolution of food-scrounging strategies within and between species. 
In: Producers and scroungers: strategies of exploitation and parasitism. (Barnard CJ, ed.) London: Croom Helm. p. 95-127

Bates D, Maechler M, Bolker B, Walker S (2014) lme4: Linear mixed-effects model using Eigen and S4. R package version 1.1-6. Available at: http://CRAN.R-project.org/package=lme4 (accessed April 2015).

Bleiweiss R (1985) Iridescent polychromatism in a female hummingbird: is it related to feeding strategies? The Auk 102: 701-713.

Brown JL, Orians GH (1970) Spacing patterns in mobile animals. Annu Rev Ecol Evol Syst 1: 239-262. doi.org/10.1146/annurev.es.01.110170.001323

Burnham KP, Anderson, DR (2002) Model selection and multi-model inference: a practical information-theoretic approach. http://www.myilibrary.com (accessed March 2018).

Butcher GS, Rohwer S (1989) The evolution of conspicuous and distinctive coloration for communication in birds. In: Current ornithology. (Power DM, ed.) Vol. 6. New York: Plenum Press, 51-108

Calisi RM, Malone JH, Hews DK (2008) Female secondary coloration in the mexican boulder spiny lizard is associated with nematode load. J Zool 276: 358-367. doi: 10.1111/j.1469-7998.2008.00499.x

Camfield AF (2006) Resource value affects territorial defense by broad-tailed and rufous hummingbirds. J Field Ornithol 77: 120-125. doi: 10.1111/j.1557-9263.2006.00031.x Candolin U (2003) The use of multiple cues in mate choice. Biol Rev 78: 575-595. doi.org/10.1017/S1464793103006158

Carpenter FL, Hixon MA, Russell RW, Paton DC, Temeles EJ (1993) Interference asymmetries among age-sex clases of rufous hummingbird during migratory stopovers. Behav Ecol 
Sociobiol 33: 297-304. doi.org/10.1007/BF00172927

Chaine AS, Roth AM, Shizuka D, Lyon BE (2013) Experimental confirmation that avian plumage traits function as multiple status signals in winter contests. Anim Behav 86: 409-415. doi.org/10.1016/j.anbehav.2013.05.034

Chávez-Zichinelli CA, Gómez L, Ortiz-Pulido R, Lara C, Valdéz R, Romano MC (2014) Testosterone levels in feces predict risk-sensitive foraging in hummingbirds. J Avian Biol 45: 501-506. doi: 10.1111/jav.00387

Dearborn DC (1998) Interspecific territoriality by a rufous-tailed hummingbird (Amazilia tzacatl): effects of intruder size and resource value. Biotropica 30: 306-313. doi: 10.1111/j.1744-7429.1998.tb00064.x

Dunlap KD, Schall J (1995) Hormonal alterations and reproductive inhibition in male fence lizards (Sceloporus occidentalis) infected with the malarial parasite Plasmodium mexicanum. Physiol Zool 68: 608-621. doi.org/10.1086/physzool.68.4.30166347

Endler JA (1978) A predator's view of animal color patterns. Evol Biol 11: 319-364. doi:10.1007/978-1-4615-6956-5_5

Ewald PW, Rohwer S (1980) Age, coloration and dominance in nonbreeding hummingbirds: a test of the asymmetry hypothesis. Behav Ecol Sociobiol 7: 273-279. doi.org/10.1007/BF00300667

Ewald PW (1985) Influence of asymmetries in resource quality and age on aggression and dominance in black-chinned hummingbirds. Anim Behav 33: 705-719. doi.org/10.1016/S0003-3472(85)80001-4

Fitzpatrick S (1998) Birds' tails as signaling devices: markings, shape, length, and feather quality. Am Nat 151: 157-173. doi.org/10.1086/286109 
425 Feinsinger P, Colwell RK (1978) Community organization among neotropical nectar-feeding

426

427

428

429

430

431

432

433

434

435

436

437

438

439

440

441

442

443

444

445

446

447

birds. Am Zool 18: 779-795. doi.org/10.1093/18.4.779

Folstad I, Karter AJ (1992) Parasites, bright males, and the immunocompetence handicap. Am Nat 139: 603-622. doi: 10.1086/285346.

Fowlie MK, Krüger O (2003) The evolution of plumage polymorphism in birds of prey and owls: the apostatic selection hypothesis revisited. J Evol Biol 16: 577-583.

doi: 10.1046/j.1420-9101.2003.00564.x

Gass CL (1979) Territory regulation, tenure, and migration in rufous hummingbirds. Can J Zool 57: 914-923. doi.org/10.1139/z79-112

Goloff BM, Burch S (2012) Stress response in the rufous hummingbird (Selasphorus rufus): mechanisms of personality and social dominance. Friday Harbor Laboratories Student Research Papers. University of Washington

Gould SJ (1974) The origin and function of "bizarre" structures: antler size in the "Irish elk", Megaloceros giganteus. Evolution 28: 191-220.

doi: $10.1111 /$ j.1558-5646.1974.tb00740.x

Goodwin TW (1984) The Biochemistry of the carotenoids. Chapman and Hall, London.

Griffith SC, Parker TH, Olson VA (2006) Melanin- versus carotenoid-based sexual signals: is the difference really so black and red? Anim Behav 71: 749-63. doi.org/10.1016/j.anbehav.2005.07.016

Gustafsson L, Qvarnström A, Sheldon BC (1995) Trade-offs between life-history traits and a secondary sexual character in male collared flycatchers. Nature 375: 311-313. doi/10.1038/375311a0

Hamilton WD, Zuk M (1982) Heritable true fitness and bright birds: a role for parasites? Science 
218: 384-387. doi: 10.1126/science.7123238

Hixon MA, Carpenter FL, Paton DC (1983) Territory area, flower density, and time budgeting in hummingbirds: an experimental and theoretical analysis. Am Nat 122: 366-391. doi: $10.1086 / 284141$

Howell SN, Webb S (1995) A guide to the birds of Mexico and northern Central America. Oxford University Press.

Husak JF, Henningsen JP, Vanhooydonck B, Irschick DJ (2015) A performance-based approach to studying costs of reliable signals. In: Animal signaling and function: an integrative approach (Irschick DJ, Briffa M, Podos J, eds). John Wiley and Sons. p. 47-74.

Ingles J (1976) Observations on the hummingbirds Orthorhynchucsr istatus and Eulampis jugularis of Martinique (West Indies). Gerfaut 66: 129-132.

Justino DG, Maruyama PK, Oliveira PE (2012) Floral resource availability and hummingbird territorial behaviour on a Neotropical savanna shrub. J Ornithol 153: 189-197. doi.org/10.1007/s10336-011-0726-X

Justyn NM, Peteya JA, D’Alba L, Shawkey (2017) Preferential attachment and colonization of the keratinolytic bacterium Bacilius licheniformis on black and white-striped feathers. The Auk 134: 466-473. doi.org:10.1692/AUK-16-245.1

Krebs JR, Davies NB (1987) An Introduction to Behavioural Ecology. 2nd Edition. Blackwell Scientific Publications, Oxford.

Kodric-Brown A, Brown JH (1978) Influence of economics, interspecific competition and sexual dimorphism on territoriality of migrant rufous hummingbirds. Ecology 59: 285-296. doi:10.2307/1936374

Kodric-Brown A, Sibly RM, Brown JH (2006) The allometry of ornaments and weapons. Proc 
472

473

474

475

476

477

478

479

480

481

482

483

484

485

486

487

488

489

490

491

492

493

Natl Acad Sci USA 103: 8733-8738. doi: 10.1073/pnas.0602994103

Kose M, Møller AP (1999) Sexual selection, feather breakage and parasites: the importance of white spots in the tail of the barn swallow (Hirundo rustica). Behav Ecol Sociobiol 45: 430-436. doi.org/10.1007/s0026500505

Lara C (2006) Temporal dynamics of flower use by hummingbirds in a temperate forest in Mexico. Ecoscience 13: 23-29. doi.org/10.2980/1195-6860

Lank DB (2002) Diverse processes maintain plumage polymorphisms in birds. J Avian Biol 33: 327-330. doi: 10.1034/j.1600-048X.2002.30811.x.

Lyon BE, Montgomerie R (2012) Sexual selection is a form of social selection. Philos Trans R Soc Lond B Biol Sci 367: 2266-2273. doi: 10.1098/rstb.2012.0012

Matta NE, Lotta IA, Valkiūnas G, González AD, Pacheco MA, Escalante AA, Moncada LI, Rodríguez-Fandiño OA, 2014. Description of Leucocytozoon quynzae sp. nov.(Haemosporida, Leucocytozoidae) from hummingbirds, with remarks on distribution and possible vectors of leucocytozoids in South America. Parasitol Res 113: 457-468. doi: 10.1007/s00436-013-3675-X

McGlothlin JW, Parker PG, Nolan V Jr, Ketterson ED (2005) Correlational selection leads to genetic integration of body size and an attractive plumage trait in dark-eyed juncos. Evolution 59: 658-671. doi.org/10.1554/04-163

McGlothlin JW, Duffy DL, Henry-Freeman JL, Ketterson ED (2007) Diet quality affects an attractive white plumage pattern in dark-eyed juncos (Junco hyemalis). Behav Ecol Sociobiol 61: 1391-1399. doi: 10.1007/s00265-007-0370-х

Mercadante A, Hill GE (2014) An experimental test of the role of structural blue and melaninbased chestnut coloration in aggressive contests in male eastern bluebirds. Front Ecol 
Evol 2: 24. doi.org/10.3389/fevo.2014.00024

495

496

497

498

499

500

501

502

503

504

505

506

507

508

509

510

511

512

513

514

515

516

Møller AP (1987) Variation in badge size in male house sparrows Passer domesticus: evidence for status signalling. Anim Behav 35: 1637-1644. doi.org/10.1016/S00033472(87)80056-8

Montgomerie RD, Gass CL (1981) Energy limitation of hummingbird population in tropical and temperate communities. Oecologia 50: 162-165. doi: 10.1007/BF00348031

Muck C, Goymann W (2011) Throat patch size and darkness covaries with testosterone in females of a sex-role reversed species. Behav Ecol 22: 1312-1319. doi: 10.1093/beheco/arr133

Nakagawa S, Schielzeth H (2010) Repeatability for gaussian and non-gaussian data: a practical guide for biologists. Biol Rev 85: 935-956. doi: 10.1111/j.1469-185X.2010.00141.x

Németh Z, Moore FR (2012) Differential timing of spring passage of ruby-throated hummingbirds along the northern coast of the Gulf of Mexico. J Field Ornithol 83: 26-31. doi: 10.1111/j.1557-9263.2011.00352.x

Ornelas JF, Ordano M, Hernández A, López JC, Mendoza L, Perroni Y (2002)Nectar oasis produced by Agave marmorata Roezl. (Agavaceae) lead to spatial and temporal segregation among nectarivores in the Tehuacán Valley, México. J Arid Environ 52: 37-51. doi.org/10.1006/jare.2002.0971

Parker GA (1974) Assessment strategy and the evolution of fighting behaviour. J Theor Biol 47: 223-243. doi: 10.1016/0022-5193(74)90111-8

Pascual J, Senar JC (2014) Antipredator behavioural compensation of proactive personality trait in male Eurasian siskins. Anim Behav 90: 297-303. doi.org/10.1016/j.anbehav.2014.02.002 
517 Paton D, Caryl PG (1986) Communication by agonistic displays: 1. variation in information content between samples. Behaviour 98: 213-239. doi: 10.1163/156853979X00287

519 Petrie M (1988) Intraspecific variation in structures that display competitive ability: large animals invest relatively more. Anim Behav 36: 1174-1179. doi.org/10.1016/S00033472(88)80076-9

522 523

524 525 526 527 528 529 530 531

Petrie M (1992) Are all secondary sexual display structures positively allometric and, if so, why? Anim Behav 43: 173-175. doi.org/10.1016/S0003-3472(05)80087-9

Pitelka FA (1942) Territoriality and related problems in North American hummingbirds. The Condor 44: 189-204. doi: 10.2307/1364129

Pryke SR (2013) Bird contests: from hatching to fertilisation. In: Animal contests (Hardy IC, Briffa M, eds). Cambridge University Press, New York, NY, p. 287-303.

Pyle P (1997) Identification guide to North American birds, Part I. Bolinas, CA, Slate Creek Press.

Quesada J, Chávez-Zichinelli CA, Senar JC, Schondube JE (2013) Plumage coloration of the blue grosbeak has no dual function: A test of the armament-ornament model of sexual selection. The Condor 115: 902-909. doi: 10.1007/s00265-014-1856-y

Rat M, van Dijk RE, Covas R, Doutrelant C (2015) Dominance hierarchies and associated signalling in a cooperative passerine. Behav Ecol Sociobiol 69: 437-448. doi: $10.1007 / \mathrm{s} 00265-014-1856-\mathrm{y}$

R Core Team (2014) A language and environment for statistical computing. R Foundation for Statistical Computing, Vienna, Austria. http://www.R-project.org/ (accessed 2 April 2015).

Rémy A, Grégoire A, Perret P, Doutrelant C (2010). Mediating male-male interactions: the role 
of the UV blue crest coloration in blue tits. Behav Ecol Sociobiol. 64:1839-1847. doi: $10.1007 / \mathrm{s} 00265-010-0995-\mathrm{z}$

Ressel S, Schall JJ (1989) Parasites and showy males: malarial infection and color variation in fence lizards. Oecologia 78: 158-164. doi: 10.1007/BF00377151

Rohwer SA (1975) The social significance of avian winter plumage variability. Evolution 29: 593-610. doi: 10.1111/j.1558-5646.1975.tb00853.x

Rohwer SA (1982) The evolution of reliable and unreliable badges of fighting ability. Amer Zool 22: 531-546. doi.org/10.1093/icb/22.3.531

Salvador A, Veiga JP, Martin J, Lopez P, Abelenda M, Puerta M (1996) The cost of producing a sexual signal: testosterone increases the susceptibility of male lizards to ectoparasitic infestation. Behav Ecol 7: 145-150. doi.org/10.1093/beheco/7.2.145

Santos ES, Scheck D, Nakagawa S (2011) Dominance and plumage traits: meta-analysis and metaregression analysis. Anim Behav 82: 3-19. doi: 10.1098/rspb.2013.2361

Schuchmann KL (1999) Family Trochilidae (Hummingbirds). In: Handbook of the Birds of the World, Vol. 5 (del Hoyo J, Elliott A, Sargatal J, eds). Lynx Editions, Barcelona. p. $468-680$.

Senar J, Camerino M, Metcalfe N (1990) Familiarity breeds tolerance: the development of social stability in flocking siskins (Carduelis spinus). Ethology 85: 13-24. doi:10.1111/j.1439-0310.1990.tb00381.x

Senar JC, Camerino M, Copete JL, Metcalfe NB (1993) Variation in the black bib of the eurasian siskin (Carduelis spinus) and its role as a reliable badge of dominance. The Auk 110: 924-927. doi: 10.2307/4088649

Senar JC (2006) Color displays as intrasexual signals of aggression and dominance. In: Bird 
Coloration Volume 2 (Hill GE, McGraw KJ, eds.). Harvard University Press, p. 87-136.

Skutch AF (1940). Accounts in life histories of North American cuckoos, goatsuckers, hummingbirds and their allies (A. C. Bent). US Natl Mus Bull 176.

Smith MJ, Harper DG (1995) Animal signals: models and terminology. J Theor Biol 177: 305-311. doi.org/10.1006/jtbi.1995.0248

Smith MJ, Harper D (2003) Animal Signals. Oxford University Press, Oxford.

Sokal RR, Rohlf FJ (2012). Biometry: the principles and practice of statistics in biological research, 4th ed. Freeman, San Francisco.

Stiles FG, Wolf LL (1979) Ecology and evolution of lek mating behavior in the Long-tailed Hermit hummingbird. Ornithol Monogr 27: 1-78. doi: 10.2307/40166760

Stiles FG (1981) Geographical aspects of bird-flower coevolution, with particular reference to Central America. Ann Mo Bot Gard 68: 323-351. doi: 10.2307/2398801

Stiles FG (1982) Aggressive and courtship displays of the male Anna's hummingbird. The Condor 84: 208-225. doi: 10.2307/1367674

Stiles FG (1995) Behavioral, Ecological and morphological correlates of foraging for arthropods by the hummingbirds of a tropical wet forest. The Condor 97: 853-878. doi: $10.2307 / 1369527$

Stiles FG, Altshuler DL, Dudley R (2005). Wing morphology and flight behavior of some North American hummingbird species. The Auk 122: 872-886. doi.org/10.1642/0004-8038

Stuart-Fox DM, Moussalli A, Marshall NJ, Owens IP (2003) Conspicuous males suffer higher predation risk: visual modeling and experimental evidence from lizards. Anim Behav 66: 541-550. doi.org/10.1006/anbe.2003.2235

Studd VM, Robertson RJ (1985) Evidence for reliable badges of status in territorial yellow 
warblers (Dendroica petechia). Anim Behav 33: 1102-1113.

doi.org/10.1016/S0003-3472(85)80169-X

Tiebout HM (1996) Costs and benefits of interspecific dominance rank: are subordinates better at finding novel food locations?. Anim Behav 5: 1375-1381. doi.org/10.1006/anbe.1996.0140

Tibbetts EA, Dale J (2004) A socially enforced signal of quality in a paper wasp. Nature 423: 218-222. doi: 10.1038/nature02949

Tobias JA, Montgomerie R, Lyon BE (2012) The evolution of female ornaments and weaponry: social selection, sexual selection and ecological competition. Phil Trans R Soc B 367: 2274-2293. doi: 10.1098/rstb.2011.0280

Török J, Hegyi G, Garamszegi LZ (2003) Depigmented wing patch size is a condition-dependent indicator of viability in male collared flycatchers. Behav Ecol 14: 382-388. doi: 10.1093/beheco/14.3.382

Vedder O, Schut E, Magrath MJ, Komdeur J (2010) Ultraviolet crown colouration affects contest outcomes among male blue tits, but only in the absence of prior encounters. Funct Ecol 24: 417-425. doi: 10.1111/j.1365-2435.2009.01660.x

Villers RL, Rojas GF, Tenorio LP (2006). Botanic guide to the La Malinche National Park Tlaxcala-Puebla. Universidad Nacional Autónoma de México. México. D.F.

Young CM, Cain KE, Svedin N, Backwell PRY, Pryke SR (2015) The role of pigment based plumage traits in resolving conflicts. J Avian Biol 47: 167-175. doi: 10.1111/jav.00742

Wagner HO (1946) Food and feeding habits of Mexican hummingbirds. Willson Bull 58: 69-132.

Warton DI, Duursma RA, Falster DS, Taskinen S (2012) smatr 3 - an R package for estimation 
609

610

611 Whitfield DP (1987) Plumage variability, status signalling and individual recognition in avian

612

613 Williamson SL (2001) A field guide to hummingbirds of North America. Houghton Mifflin

614

615

616

617

618

619

620

621

622

623

624 and inference about allometric lines. Methods in Ecol Evol 3:257-259.

doi: 10.1111/j.2041-210X.2011.00153.x
Harcourt, New York.

Wolf LL (1969). Female territoriality in a tropical hummingbird. The Auk 86: 490-504.

doi: $10.2307 / 4083410$

Wolf LL, Stiles FG (1970) Evolution of pair cooperation in a tropical hummingbird. Evolution 24: 759-773. doi: 10.1111/j.1558-5646.1970.tb01811.x

Wolf LL, Stiles FG, Hainsworth FR (1976) Ecological organization of a tropical, highland hummingbird community. J Anim Ecol 45: 349-379. doi: 10.2307/3879

Zahavi A (1975) Mate selection—a selection for a handicap. J Theor Biol 53: 205-214.

doi.org/10.1016/0022-5193(75)90111-3 
626 Figure 1. Relationship between the difference in the number of visits to a feeder and the difference in 627 the supercilium size between contenders. Dyads had bird contenders with similar (black dots) or 628 different (open dots) badge size. The relationship was significant for both similar $(\mathrm{Y}=0.59 \mathrm{x}-0.13$, $\left.629 \mathrm{R}^{2}=0.34, N=11, P<0.01\right)$ and different contest types $\left(\mathrm{Y}=0.86 \mathrm{x}+3.02, \mathrm{R}^{2}=0.71, N=10, P<0.01\right)$, and 630 the comparison of both slopes showed that they are statistically different $(\mathrm{t}=4.281$, d.f. $=18, P<0.001)$. 631 Photograph of a White-eared hummingbird male showing his supercilium is by Carlos Lara. 
632 Table 1. Slopes, 95\% confidence intervals (CIs), $R^{2}$, and $P$ values obtained from MA regressions 633 fitted between supercilium size (dependent variable) and six body-size measurements of White634 eared hummingbird males. All values were $\log _{10}$ transformed prior to analyses.

\begin{tabular}{lcccc}
\hline Body measurement & Slope & Lower CI, Upper CI & $\boldsymbol{R}^{2}$ & $\boldsymbol{P}^{2}$ value \\
\hline Body mass & 34.788 & $5.227-7.660$ & 0.003 & 0.711 \\
Bill length & -29.000 & $39.764-10.597$ & 0.033 & 0.248 \\
Body length & 51.395 & $17.858-58.723$ & 0.029 & 0.287 \\
Tail length & 48.128 & $8.743-13.802$ & 0.005 & 0.651 \\
Tarsus length & -13.484 & $18.969-4.914$ & 0.038 & 0.240 \\
Wing chord & 39.381 & $14.286-52.327$ & 0.032 & 0.255 \\
\hline
\end{tabular}


1 Table 2. Results from Bayesian model averaging analyses for parameters affected by the

2 supercilium size difference among contenders. Shown are posterior inclusion probabilities (PIP)

3 and estimates of standardised mean coefficients (PMCs) for each dependent variable. The higher

4 PIPs signify the importance of a dependent variable to be included in the true model. All models

$5 \quad$ included Contest identity as random effects.

6

\begin{tabular}{lll}
\hline Dependent variables & PIP & PMC \\
\hline Number of visits & 0.683 & 0.024 \\
Duration of visits & 0.480 & -0.013 \\
Latency of visits & 0.160 & 0.025 \\
Contest type & 0.158 & 0.017 \\
Number of disputes & 0.140 & 0.089 \\
\hline
\end{tabular}

7 


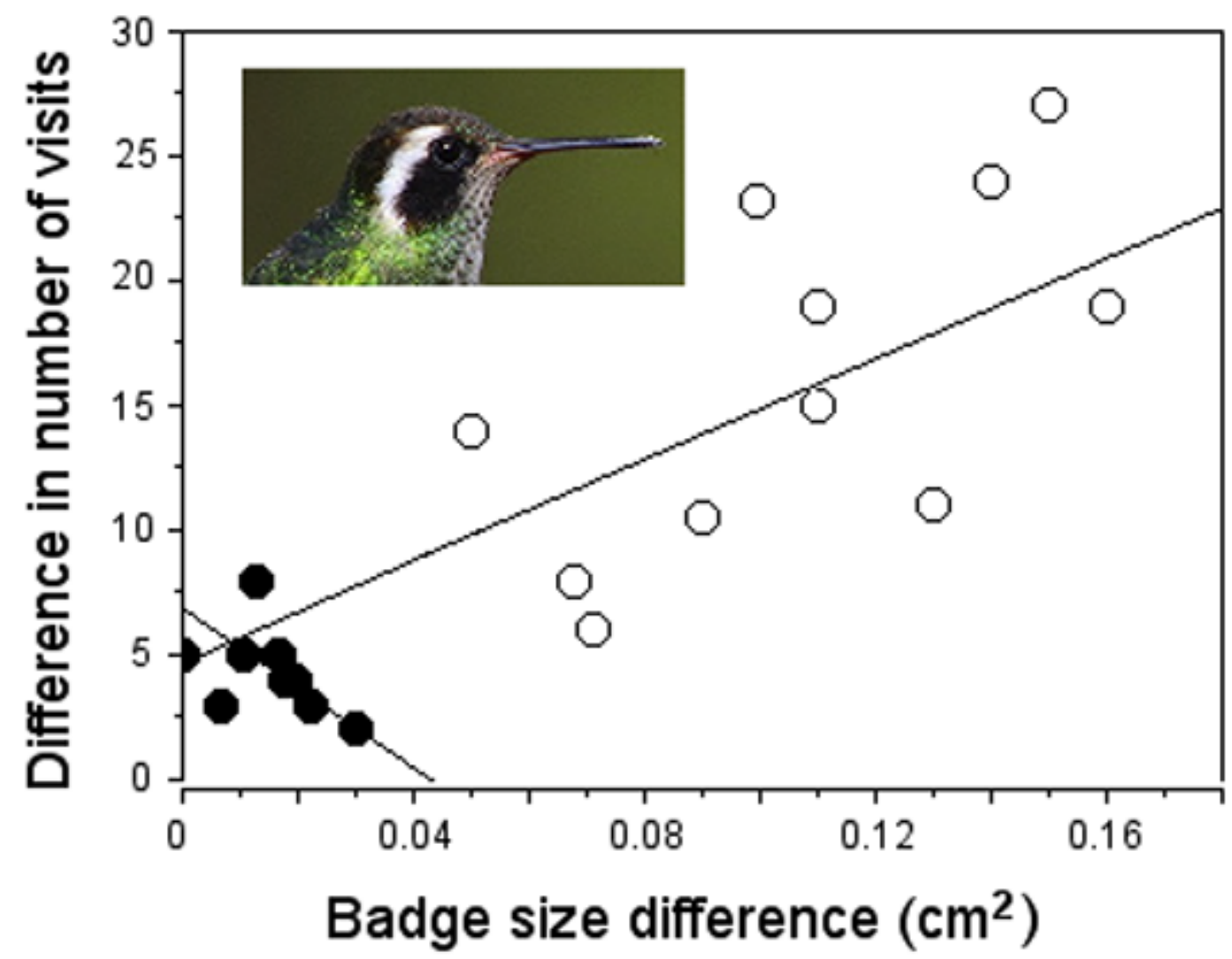

16

17 